\title{
Association between lipid-lowering agents and severe hyponatremia: a population-based case-control study
}

\author{
Jakob Skov ${ }^{1,2} \cdot$ Henrik Falhammar $^{1,3} \cdot$ Jan Calissendorff ${ }^{1,3} \cdot$ Jonatan D Lindh $^{4} \cdot$ Buster Mannheimer $^{5}$ (D)
}

Received: 12 May 2020 / Accepted: 18 September 2020 / Published online: 19 November 2020

(C) The Author(s) 2020

\begin{abstract}
Purpose Drug-induced hyponatremia is common, with medications from many drug-classes implicated. Lipid-lowering agents are among the most prescribed drugs. Limited evidence suggests an inverse association between statins and hyponatremia, while data on other lipid-lowering agents is absent. The objective of this investigation was to study the association between lipidlowering drugs and hospitalization due to hyponatremia.

Methods This was a register-based case-control study of the general Swedish population. Those hospitalized with a main diagnosis of hyponatremia $(n=11,213)$ were compared with matched controls $(n=44,801)$. Multivariable logistic regression adjusting for co-medication, diseases, previous hospitalizations, and socioeconomic factors was used to explore the association between severe hyponatremia and the use of lipid-lowering drugs.

Results Unadjusted ORs (95\% CI) for hospitalization due to hyponatremia were $1.28(1.22-1.35)$ for statins, 1.09 (0.79-1.47) for ezetimibe, $1.38(0.88-2.12)$ for fibrates, and $2.12(1.31-3.35)$ for resins. After adjustment for confounding factors the adjusted odds ratios $(95 \% \mathrm{CI})$ compared with controls were $0.69(0.64-0.74)$ for statins, $0.60(0.41-0.86)$ for ezetimibe, $0.87(0.51-1.42)$ for fibrates, and $1.21(0.69-2.06)$ for resins.

Conclusions Use of statins and ezetimibe was inversely correlated with severe hyponatremia. Consequently, these drugs are unlikely culprits in patients with hyponatremia, and they appear safe to initiate in hyponatremic patients. A potential protective effect warrants further studies on how statins and other lipid-lowering drugs are linked to dysnatremias.
\end{abstract}

Keywords Hospitalization · Statin · Ezetimibe $\cdot$ SIADH $\cdot$ Adverse reaction $\cdot$ Electrolyte

Electronic supplementary material The online version of this article (https://doi.org/10.1007/s00228-020-03006-8) contains supplementary material, which is available to authorized users.

Buster Mannheimer

buster.mannheimer@sll.se

1 Department of Molecular Medicine and Surgery, Karolinska Institutet, Stockholm, Sweden

2 Department of Medicine, Karlstad Central Hospital, Karlstad, Sweden

3 Department of Endocrinology, Metabolism and Diabetes, Karolinska University Hospital, Stockholm, Sweden

4 Department of Laboratory Medicine, Division of Clinical Pharmacology, Karolinska University Hospital Huddinge, Karolinska Institutet, Stockholm, Sweden

5 Department of Clinical Science and Education, Södersjukhuset, Karolinska Institutet, Stockholm, Sweden

\section{Introduction}

Hyponatremia, usually defined as a serum sodium below 135 $\mathrm{mmol} / \mathrm{L}$, is the most common electrolyte disturbance, affecting between 10 and $30 \%$ of hospitalized patients [1]. Acute symptomatic hyponatremia is a rare condition presenting with symptoms such as severe nausea, seizures, coma, and ultimately death if prompt treatment is not initiated [2]. In chronic hyponatremia, the clinical panorama is more inconspicuous, but fatigue, gait instability, and cognitive deficits are common $[3,4]$. Despite milder symptoms, chronic hyponatremia is a marker of poor clinical outcome, associated with longer durations of stay [5], higher readmission rates [6], and increased risk of death from underlying diseases $[7,8]$ when compared with normonatremic patients. For unknown reasons, the risk of death appears to be more pronounced in men than in women [9]. The most common cause of hyponatremia is medications [10], with drugs across most clinical fields implicated in hyponatremia [11-15]. A select few drugs, primarily 
antidiabetic agents [16] and lithium [17] have also been associated with a reduced risk of hyponatremia, whereas evidence is missing or inconclusive for most compounds.

In theory, statins could cause fluid retention and hyponatremia through a mechanism similar to syndrome of inappropriate antidiuretic hormone secretion (SIADH), as they have been shown to increase renal expression of aquaporin-2 independent of arginine vasopressin and to reduce diuresis in rat models with central diabetes insipidus [18]. Observational data on patients with lithium-induced diabetes insipidus, indicating different urine osmolality in statin users and non-users, has also been published [19]. However, despite their frequent use, data on lipid-lowering agents and hyponatremia is scarce. Searching VigiBase, the World Health Organization global database of individual case safety reports [20] from inception up to July 10, 2020, returns 374 reports of hyponatremia as a suspected adverse reaction of treatment with statins (simvastatin, atorvastatin, rosuvastatin, pravastatin, fluvastatin, lovastatin) or ezetimibe. This corresponds to $0.1 \%$ of submitted reports for these compounds. To the best of our knowledge, no studies reporting on increased risk of hyponatremia in patients treated with statins have been published. To the contrary, the limited data available suggests a modest inverse association between statins and hyponatremia [21-23]. while data on other lipid-lowering agents is absent. This could signal that these drugs are safe, or even offer limited protection from hyponatremia, but current data is insufficient to support such conclusions.

Hence, the aim of this study was to explore the association between treatment with lipid-lowering agents and hospitalization due to hyponatremia.

\section{Methods}

This was a retrospective population-based case-control study on the adult Swedish population. Cases were defined as subjects, 18 years or older, in the National Patient Register (NPR) [24], hospitalized with a first-ever main diagnosis of hyponatremia (E87.1) or SIADH (E22.2) between October 1, 2005, and December 31, 2014. A first ever diagnosis was defined as absence of a prior diagnosis (main or secondary) of E87.1 or E22.2 dating back to January 1, 1997. For every case, four controls without a previous diagnosis of hyponatremia (main or secondary diagnosis since January 1, 1997) were randomly identified from the Total Population Register[24]. Controls were matched for age, sex, and municipality. During this time-period (January 1, 1997, to December 31, 2014), all diagnoses in the NPR were recorded according to the International Classification of Diseases, Tenth Revision (ICD-10). Concurrent and previous use of medications was identified using the Swedish Prescribed Drug Register (SPDR), which contains individual data on all prescription drugs dispensed in Sweden, dating back to July 1, 2005 [25]. The longitudinal integration database for health insurance and labour market studies register (LISA) was used to collect data on socioeconomic status [26]. The recruitment process has been described in more detail in a previous work [27]. The study was approved by the Regional Ethical Review Board in Stockholm. Informed consent was waived.

\section{Variables}

Variables of interest (lipid-lowering agents) identified by corresponding Anatomical Therapeutic Chemical (ATC) codes along with other exposure variables are listed in Table 1. Drug exposure was defined as a documented dispensing within 90 days prior to the index date, i.e., the date of hospitalization due to hyponatremia. Confounding factors accounted for in the statistical analysis included concurrent medications, socioeconomic factors, and medical conditions identified by collating information from the NPR, the SPDR, and LISA. Lipidlowering therapy is often initiated shortly after cardiovascular events (secondary prevention). In an effort to optimize adjustment of confounders we therefore treated cardiovascular events occurring within 90 days of a main diagnosis of hyponatremia, versus older events, as separate confounders. Due to the large number of variables, intermediate models gradually adjusting for confounding factors were calculated by adding variables for comorbid conditions, for concurrent medications, and for socioeconomic factors and frailty to the crude model in a step-by step fashion. Finally, in a post hoc analysis exploring the combined effect of statins and ezetimibe, we considered use of statins only, ezetimibe only, and the combined use of statins and ezetimibe as three independent (non-interacting) variables.

\section{Statistical analysis}

To study the association between hyponatremia and lipidlowering agents, we used univariable and multivariable logistic regression. The association between hyponatremia and the different lipid-lowering agents was presented as crude and adjusted (for potential confounders) odds ratios (OR) with 95 confidence intervals. A $p<0.05$ was considered significant. All calculations were performed using $\mathrm{R}$ version 3.6.1 [28].

\section{Results}

In total, 35,469 individuals were hospitalized with a first-ever diagnosis of hyponatremia during the study period. Of those, 24,191 individuals with hyponatremia as a secondary diagnosis and 65 individuals under the age of 18 at the index date were excluded, yielding a final sample of 11,213 individuals 
Table 1 Variables included in the multiple logistic regression analysis and their definition

\begin{tabular}{|c|c|}
\hline Variables & Codes \\
\hline Drugs of primary interest & ATC codes beginning with: \\
\hline Lipid-lowering agents & $\mathrm{C} 10$ \\
\hline Statins & $\mathrm{C} 10 \mathrm{AA}, \mathrm{C} 10 \mathrm{~B}$ \\
\hline Simvastatin & C10AA01, C10BA02, C10BA04 \\
\hline Lovastatin & C10AA02, C10BA01 \\
\hline Pravastatin & C10AA03, C10BA03 \\
\hline Fluvastatin & C10AA04, \\
\hline Atorvastatin & C10AA05, C10BA05 \\
\hline Rosuvastatin & C10AA07, C10BA06 \\
\hline Fibrates & $\mathrm{C} 10 \mathrm{AB}, \mathrm{C} 10 \mathrm{BA} 03, \mathrm{C} 10 \mathrm{BA} 04$ \\
\hline Bezafibrate & $\mathrm{C} 10 \mathrm{AB} 02$ \\
\hline Gemfibrozil & C10AB04 \\
\hline Fenofibrate & C10AB05, C10BA03, C10BA04 \\
\hline Resins & $\mathrm{C} 10 \mathrm{AC}$ \\
\hline Cholestyramine & $\mathrm{C} 10 \mathrm{AC} 01$ \\
\hline Colestipol & $\mathrm{C} 10 \mathrm{AC} 02$ \\
\hline Colesevelam & $\mathrm{C} 10 \mathrm{AC} 04$ \\
\hline Nicotinic acid & $\mathrm{C} 10 \mathrm{AD}$ \\
\hline Nicotinic acid & C10AD02, C10AD52 \\
\hline Cholesterol absorption inhibitor & C10AX09, C10BA02, C10BA05, C10BA06 \\
\hline Ezetimibe & C10AX09, C10BA02, C10BA05, C10BA06 \\
\hline \multicolumn{2}{|l|}{ Concurrent medications } \\
\hline \multicolumn{2}{|l|}{ Antiepileptic drugs } \\
\hline Carbamazepine & N03AF01 \\
\hline Oxcarbazepine & N03AF02 \\
\hline Phenytoin & N03AB02 \\
\hline Valproate & N03AG01 \\
\hline Lamotrigine & N03AX09 \\
\hline Levetiracetam & N03AX14 \\
\hline Gabapentin & N03AX12 \\
\hline \multicolumn{2}{|c|}{ Diuretics and drugs acting on the renin-angiotensin system } \\
\hline Furosemide & $\mathrm{C} 03 \mathrm{C}$ \\
\hline Thiazides & C03A, C09BA, C09DA, C03EA \\
\hline Agents acting on the renin-angiotensin system & $\mathrm{C} 09$ \\
\hline \multicolumn{2}{|l|}{ Antibiotics } \\
\hline Fluoroquinolones & J01MA \\
\hline Macrolides & J01FA \\
\hline Trimethoprim sulfamethoxazole & J01EE \\
\hline \multicolumn{2}{|l|}{ Antidepressants } \\
\hline Serotonin reuptake inhibitors & N06AB \\
\hline Tricyclic antidepressants & N06AA \\
\hline Other antidepressants & N06AX \\
\hline \multicolumn{2}{|l|}{ Other drugs } \\
\hline Amiodarone & C01BD01 \\
\hline Desmopression & H01BA02 \\
\hline Antipsychotics & N05A excluding N05AN \\
\hline Lithium & N05AN \\
\hline Proton pump inhibitors & A02BC, A02BD06 \\
\hline Comorbidities & ICD10 codes beginning with: \\
\hline
\end{tabular}


Table 1 (continued)

\begin{tabular}{|c|c|}
\hline Variables & Codes \\
\hline \multicolumn{2}{|l|}{ Renal diseases } \\
\hline Renal insufficiency & N17-19, procedure codes DR016, DR024, KAS00, KAS10, KAS20 \\
\hline \multicolumn{2}{|l|}{ Infections } \\
\hline Sepsis & A $41 \leq 90$ days from index date \\
\hline Pneumonia & $\mathrm{J} 18 \leq 90$ days from index date \\
\hline Meningitis & G00-G07 $\leq 90$ days from index date \\
\hline \multicolumn{2}{|l|}{ Heart and vascular diseases } \\
\hline Ischaemic heart disease, recent & I $20-24 \leq 90$ days from index date \\
\hline Ischaemic heart disease, old & I20-24 > 90 days from index date, I 25 \\
\hline Congestive heart failure & $\mathrm{I} 50$ \\
\hline Cerebrovascular diseases, recent & I60-64 $\leq 90$ days from index date \\
\hline Cerebrovascular diseases, old & I60-64 > 90 days from index date, I69 \\
\hline \multicolumn{2}{|l|}{ Gastrointestinal diseases } \\
\hline Pancreatic disease & K85, K860-1 \\
\hline Inflammatory bowel disease & K50-51 \\
\hline Liver diseases & K70-77 procedure codes JJB, JJC \\
\hline \multicolumn{2}{|l|}{ Other diseases } \\
\hline Hypothyroidism & E03, E06.3 \\
\hline Malnutrition & E43.9, E41.9 \\
\hline COPD & $\mathrm{J} 44$ \\
\hline Pulmonary embolism & $\mathrm{I} 26$ \\
\hline Malignancy & $\mathrm{C}$ \\
\hline & Combination of ATC and ICD10 codes, each beginning with: \\
\hline Alcoholism & $\begin{array}{l}\text { ATC: N07BB03, N07BB04, N07BB01, N07BB05, N07BB } \\
\text { ICD10: E244, F10, G312, G621, G721, I426, K292, K70, K860, O354, } \\
\text { P043, Q860, T51, Y90-91, Z502, Z714 }\end{array}$ \\
\hline Adrenal insufficiency & $\begin{array}{l}\text { ATC: H02AA, H01BA } \\
\text { ICD10: E27.1, E27.2, E27.3, E27.4, E25 }\end{array}$ \\
\hline Diabetes mellitus & $\begin{array}{l}\text { ATC: A10 } \\
\text { ICD10: E10-E14 }\end{array}$ \\
\hline \multicolumn{2}{|l|}{ Socioeconomic factors/frailty } \\
\hline Education & Increasing levels of education from 1 to 6 , ordinal variable \\
\hline Income & Annual income in Swedish krona, continuous variable \\
\hline Unemployment & Number of days, continuous variable \\
\hline Drug use & $\begin{array}{l}\text { Number of dispensed drugs } 90 \text { days prior to index date, } \\
\text { categorized into }<4,4-7,8-12 \text {, and }>12 \text { drugs }\end{array}$ \\
\hline Duration of hospitalization & $\geq 3$ days \\
\hline
\end{tabular}

ATC Anatomical Therapeutic Chemical, COPD chronic obstructive pulmonary disease, ICD International Classification of Diseases

with a main diagnosis of hyponatremia. For every case, four controls $(n=44,801)$ were matched at the index date. The median age in the total cohort was 76 years (interquartile range 65-84 years), with women accounting for $72 \%$. Clinical characteristics of cases and matched controls, alongside with data on use of lipid-lowering agents, are presented in Table 2. Overall, cases carried a greater comorbid burden than their matched controls. They used more medications and were more likely to have a history of inpatient care. The most common concomitant diseases included hypertension, ischemic heart disease, diabetes, alcoholism, congestive heart failure, cerebrovascular disease, and chronic obstructive pulmonary disease. Statins were by far the most commonly used lipid-lowering agents, with $20.1 \%$ of cases $(n=2,249)$ and $16.4 \%$ of controls $(n=7,333)$ on statin therapy. The second most common drug was ezetimibe. Resin-prescriptions were largely accounted for by cholestyramine, usually prescribed as a bile acid sequestrant rather than a lipid-lowering agent in 
Table 2 Medical characteristics (selection of variables from Table 1) and use of lipid-lowering agents

Number $(\%)$ of total cases $(n=11,213) \quad$ Number $(\%)$ of total controls $(n=44,801)$

\begin{tabular}{|c|c|c|}
\hline \multicolumn{3}{|l|}{ Diagnosis } \\
\hline Malignancy & $3096(27.6)$ & $9149(20.4)$ \\
\hline Ischemic heart disease, recent $^{1}$ & $498(4.4)$ & $405(0.9)$ \\
\hline Ischemic heart disease, old ${ }^{2}$ & $1918(17.1)$ & $6072(13.6)$ \\
\hline Diabetes mellitus & $1939(17.3)$ & $5277(11.7)$ \\
\hline Alcoholism & 1764 (15.7) & $833(1.9)$ \\
\hline Congestive heart failure & $1453(13.0)$ & $3533(7.9)$ \\
\hline Cerebrovascular disease, recent & $218(1.9)$ & $164(0.3)$ \\
\hline Cerebrovascular disease, old & 1299 (11.6) & $3410(7.6)$ \\
\hline COPD & $1125(10.0)$ & $1576(3.5)$ \\
\hline Hypothyroidism & $1139(10.2)$ & $1994(4.5)$ \\
\hline Renal disease & 489 (4.4) & $888(2.0)$ \\
\hline Adrenal insufficiency & $460(4.1)$ & $300(0.7)$ \\
\hline Liver disease & $421(3.8)$ & $332(0.7)$ \\
\hline Pancreatic disease & $252(2.2)$ & $395(0.9)$ \\
\hline $\mathrm{IBD}^{4}$ & $221(2.0)$ & $444(0.1)$ \\
\hline \multicolumn{3}{|l|}{ Medications } \\
\hline Antidepressants & $2817(25.1)$ & $5745(12.8)$ \\
\hline Antipsychotics & $772(6.9)$ & $1096(2.4)$ \\
\hline Antiepileptic drugs & $1061(9.5)$ & $1128(2.5)$ \\
\hline Furosemide & 1735 (15.5) & $5487(12.2)$ \\
\hline Thiazide diuretics & $4364(38.9)$ & $6103(13.6)$ \\
\hline \multicolumn{3}{|l|}{ Proxy for frailty } \\
\hline \multicolumn{3}{|l|}{ Number of dispensed drugs 90 days prior to index date } \\
\hline$<4$ drugs & $2215(19.8)$ & $22,892(51.1)$ \\
\hline 4-7 drugs & $3421(30.5)$ & 12,967 (28.9) \\
\hline $8-12$ drugs & $3558(31.7)$ & $7010(15.6)$ \\
\hline$>12$ drugs & $2019(18.0)$ & $1.932(4.3)$ \\
\hline Number of patients with $\geq 1$ hospitalization $\geq 3$ days duration & $4852(43.2)$ & $9477(21.2)$ \\
\hline \multicolumn{3}{|l|}{ Lipid-lowering medications } \\
\hline Any lipid-lowering drug & 2314 (20.6) & 7525 (16.7) \\
\hline Statins & $2249(20.1)$ & 7333 (16.4) \\
\hline Simvastatin & $1823(16.2)$ & $5940(13.3)$ \\
\hline Pravastatin & $69(0.6)$ & $212(0.5)$ \\
\hline Fluvastatin & $1(<0.1)$ & $11(<0.1)$ \\
\hline Atorvastatin & $324(2.9)$ & 1009 (2.3) \\
\hline Rosuvastatin & $56(0.5)$ & $197(0.4)$ \\
\hline Lovastatin & $0(0)$ & $0(0)$ \\
\hline Fibrates & $27(0.2)$ & $78(0.2)$ \\
\hline Bezafibrate & $8(0.1)$ & $23(0.1)$ \\
\hline Gemfibrozil & $14(0.1)$ & $42(0.1)$ \\
\hline Fenofibrate & $5(<0.1)$ & $13(<0.1)$ \\
\hline Resins & $27(0.2)$ & $51(0.1)$ \\
\hline Cholestyramine & $25(0.2)$ & $44(0.1)$ \\
\hline Colestipol & $2(<0.1)$ & $7(<0.1)$ \\
\hline Colesevelam & $0(0.0)$ & $0(0.0)$ \\
\hline Nicotinic acid & $0(0.0)$ & $2(<0.1)$ \\
\hline Ezetimibe & $51(0.4)$ & $187(0.4)$ \\
\hline
\end{tabular}

${ }^{1}$ Within 90 days of index date; ${ }^{2}$ more than 90 days from index date; ${ }^{3}$ chronic obstructive pulmonary disease; ${ }^{4}$ inflammatory bowel disease

Sweden. Unadjusted ORs for hospitalization due to hyponatremia ranged from 1.09 (95\% CI 0.79-1.47) for ezetimibe to 2.12 (95\% CI 1.31-3.35) for resins. After adjustment for confounding factors, ORs decreased considerably, ranging from 0.60 (95\% CI $0.41-0.86)$ for ezetimibe, 0.69 (95\% CI $0.64-0.74)$ for statins, 0.87 (95\% CI $0.51-$ 1.42) for fibrates to 1.21 (95\% CI $0.69-2.06)$ for resins. The unadjusted and adjusted associations are presented in Fig. 1.
Results of the intermediate models demonstrated a gradual reduction in crude odds ratios after first adjusting for comorbidities and then for concurrent medications, but only a marginal effect from adjusting for socioeconomic factors (Supplementary materials Table S1). In the post-hoc analysis, after adjustment for confounders, ORs were $0.69(95 \% \mathrm{CI}$ 0.64-0.74) for statins, 0.54 (95\% CI 0.31-0.90) for ezetimibe, and 0.45 (95\% CI $0.27-0.73$ ) for use of both statins and ezetimibe. 
Fig. 1 Unadjusted (black diamonds) and adjusted (white diamonds) odds ratios (ORs), including $95 \%$ confidence intervals $(95 \% \mathrm{CI})$ for hospitalization due to hyponatremia in patients using lipid-lowering agents. The following substances had few users that are therefore not presented separately but are included in calculations at drug-class level: fluvastatin and lovastatin (statins), bezafibrate and fenofibrate (fibrates), colesevelam, and colestipol (resins). Nicotinic acid, used by two subjects, is included in calculations on the overall effect of any lipid-lowering agent
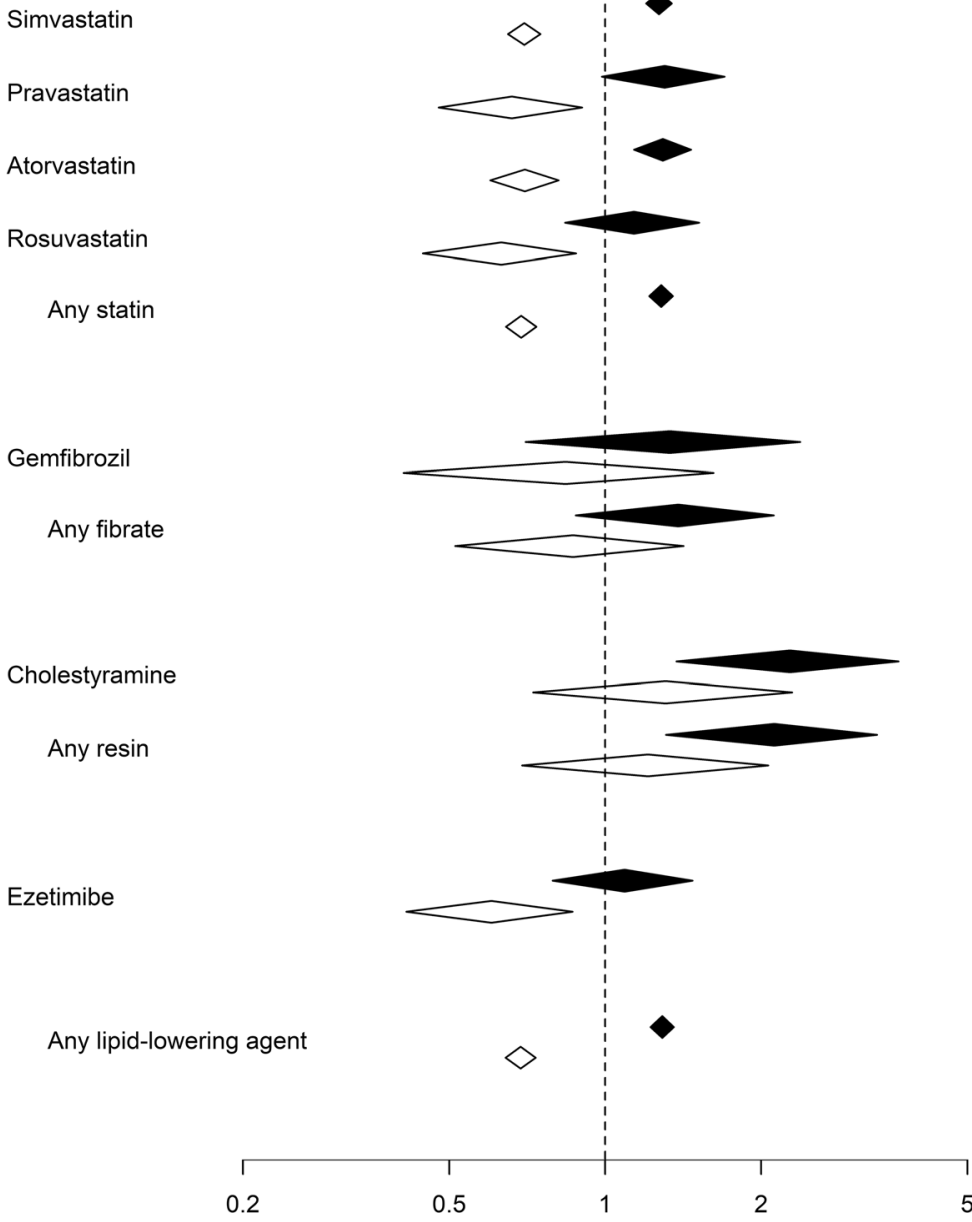

$1.27(1.20 ; 1.34)$ $0.70(0.65 ; 0.75)$ $<0.001$

$1.30(0.99 ; 1.70) \quad 0.06$ $0.66(0.48 ; 0.90) \quad<0.05$ $1.29(1.14 ; 1.46) \quad<0.001$ $0.70(0.60 ; 0.81) \quad<0.001$ $1.14(0.84 ; 1.52) \quad 0.40$ $0.63(0.44 ; 0.88) \quad<0.01$ $1.28(1.22 ; 1.35) \quad<0.001$ $0.69(0.64 ; 0.74) \quad<0.001$

\section{$1.33(0.70 ; 2.38) \quad 0.35$} $0.84(0.41 ; 1.62) \quad 0.61$ $1.38(0.88 ; 2.12) \quad 0.15$ $0.87(0.51 ; 1.42) \quad 0.58$

\section{Discussion}

In this case-control study on the general Swedish population, we demonstrated that use of statins and ezetimibe was inversely correlated with hospitalization due to hyponatremia after adjusting for multiple confounders. For resins and fibrates results were inconclusive.

Lipid-lowering agents are among the most prescribed drugs today, with more than $40 \%$ of elderly ( $>65$ years) US citizens using statins [29]. This is also the age-group most often affected by hyponatremia, with serum sodium levels below 135 $\mathrm{mmol} / \mathrm{L}$ found in up to $20 \%$ of elderly during hospitalization [30]. Despite their co-occurrence, surprisingly little is known about statins and other lipid-lowering agents in relation to hyponatremia. Instead, the absence of evidence [11] is sometimes used as evidence of absence in clinical practice, despite the inherent risk with such strategies. Here, we report an inverse association between severe hyponatremia and the use of statins and ezetimibe. For fibrates, results were similar, but did not reach statistical significance. By contrast, resins showed a non-significant increase in risk of hyponatremia, but for resins, results are difficult to interpret in this context, as cholestyramine, a drug primarily used to treat gastrointestinal diseases, accounted for most prescriptions.

Our findings on statins are corroborated by a recent study by Israel et al., reporting an inverse association between statinuse and hyponatremia in participants from the SPRINT study [21]. The potential mechanism by which statins and ezetimibe could potentially reduce the risk of severe hyponatremia is unknown. The similarity in magnitude and direction of association observed here could imply that the correlation is explained by alterations in lipid levels rather than by the drugs themselves. However, this explanation is contradicted by the study by Israel et al. showing that statin use was inversely associated with the development of hyponatremia after adjustment for multiple factors, including C-HDL levels [21]. Statins are known to exert pleiotropic effects beyond inhibition of 3-hydroxy-3-methylglutaryl coenzyme A [31], and short-term exposure to atorvastatin has been shown to decrease fractional urinary excretion of sodium in healthy subjects and in individuals with type- 2 diabetes. This may therefore constitute a mechanism [32, 33]. Nevertheless, the most 
reasonable explanation to a potential inverse association is perhaps that the preservation of glomerular filtration rate associated with use of lipid-lowering agents [34, 35] also slows the decline in capacity for electrolyte free water clearance, thus reducing the risk of fluid retention and hyponatremia. In the post hoc analysis, the OR for combined use of both statins and ezetimibe was lower than the OR for use of either compound alone, consistent with an additive effect. This observation does not provide obvious clues to the underlying mechanism, as it is consistent with both direct effects from the drugs, and indirect effects from altered lipid-profiles, but it does support an inverse association between statins and hyponatremia, as do findings from smaller studies similar to ours [21-23]. Still, pending additional data in support of a protective effect from lipid-lowering drugs with regard to hyponatremia, the most prudent conclusion is perhaps that lipid lowering agents, statins and ezetimibe in particular, are unlikely to cause or contribute to severe hyponatremia.

\section{Limitations}

The main limitation of this study is the lack of laboratory data, plasma sodium concentrations in particular, that are not recorded in the Swedish national health registries. It is important to note that the sensitivity for hyponatremia (serum sodium $<135 \mathrm{mmol} / \mathrm{L}$ ) using diagnostic records is poor [36]. On the other hand, with the clinical panorama of hyponatremia ranging from subtle to severe symptoms, using a main diagnosis of hyponatremia rather than secondary diagnoses, diagnoses made in outpatient care, or laboratory data to define cases, allowed us to limit cases to patients with clinically relevant hyponatremia, and ascertain that hyponatremia was indeed the condition that first and foremost motivated inpatient care. This was demonstrated in a previous validation showing that $89 \%$ of subjects receiving a main diagnosis of hyponatremia had been hospitalized primarily due to symptoms of hyponatremia and that the mean plasma sodium concentration (adjusted for glucose) was $121 \mathrm{mmol} / \mathrm{L}$ [27]. This, in combination with a population-based design including all Swedish residents during almost a decade, is a major strength compared with smaller studies. The finding of a reversed association may seem surprising and raise the question of potential bias attributed to the methodology. The cohort used in the present study has indeed previously been used to further characterize several groups of drugs known to increase the risk for hyponatremia using a similar design. Thus, newly initiated serotonergic antidepressants were associated with markedly elevated adjusted ORs of around 5 [27]. The increased risk attributed to antiepileptic was even larger [13]. However, the fact that our methodology is capable of addressing increased associations does not exclude the possibility of bias distorting the results. Many different disease mechanisms, sometimes overlapping, can lead to hyponatremia. Our model therefore included a wide range of concurrent illnesses and medications with known association with hyponatremia. In addition, we also included socioeconomic factors and frailty, variables that are linked to several types of severe disease. For example, socioeconomic status is linked to alcoholism and smoking, variables that are not sufficiently reflected in the registers used, which in turn may contribute to residual confounding. However, according to the stepwise model, socioeconomic factors only had a marginal effect on hospitalization (Supplementary materials Table S1). Matching hospitalized patients with population controls introduces the risk of information bias. This risk is most apparent with the NPR, as this register includes diagnoses collected from hospital associated care only (inpatient and outpatient), whereas the SPDR, which includes information on drugs prescribed in primary health care as well, is less sensitive to this bias. The inclusion of numerous variables could potentially introduce bias due to over-adjustment. However, the one-in-ten-rule suggests that one variable could be included for every ten cases included without running the risk of overfitting. Over 11,000 cases in the current study may therefore motivate the use of 61 independent variables and still keeping risk of over fitting low. For increased understanding of what factors were responsible for the considerable shift from significantly increased to significantly decreased risk of hyponatremia we included intermediate models that built on the crude model by step-by-step adding of confounders in groups of comorbidities, concurrent medications, and socioeconomic factors. As evident from the results, adjusting for medications appeared most important (supplemental Table 1). Furthermore, defining drug-use by prescriptions filled within the last 90 days may have resulted in some misclassifications, as statin-users are known to show large variation in persistence with many people stopping and starting treatment [37]. Finally, the study spans over a long period of time. An additional source of potential residual confounding may come from changes in prescribing patterns for example due to the new reimbursement scheme for lipid lowering agents introduced in 2009 [38]. The effects of such time-dependent effect are however difficult to predict.

In conclusion, we found an inverse association between statins/ezetimibe and hospitalization due to hyponatremia. The implication of these observations is that most lipid-lowering agents are likely to be safe for continued use in patients with hyponatremia of unknown origin, and safe to initiate, even in patients at high risk of hyponatremia. Causal relationships cannot be established with certainty using observational data, but a potential protective effect warrants further studies on how statins and other lipid-lowering drugs are linked to dysnatremias.

Authors' contributions Study design/concept: All authors; Data acquisition/analysis: All authors; Mentorship and data interpretation: All authors; Statistical analysis: JDL. Each author contributed important intellectual content during manuscript drafting or revision and accepts 
accountability for the overall work by ensuring that questions pertaining to the accuracy or integrity of any portion of the work are appropriately investigated and resolved.

Funding Open access funding provided by Karolinska Institute. The cost for retrieval, analysis, and presentation of the data was funded by a clinical trial investigating for the development of diabetic neuropathy (Cebix incorporated, grant number CBX129801-DN-201) and the Stockholm County Medical Committee (grant number HSTV18048). The funders did not have a role in study design; data collection, analysis, or reporting; or the decision to submit for publication.

Data availability Data will be made available upon reasonable requests.

\section{Compliance with ethical standards}

Conflict of interest Drs. Jakob Skov and Buster Mannheimer report previous consultancy fees from Otsuka Pharma Scandinavia AB, outside the submitted work. No other authors had any conflicts of interest.

Open Access This article is licensed under a Creative Commons Attribution 4.0 International License, which permits use, sharing, adaptation, distribution and reproduction in any medium or format, as long as you give appropriate credit to the original author(s) and the source, provide a link to the Creative Commons licence, and indicate if changes were made. The images or other third party material in this article are included in the article's Creative Commons licence, unless indicated otherwise in a credit line to the material. If material is not included in the article's Creative Commons licence and your intended use is not permitted by statutory regulation or exceeds the permitted use, you will need to obtain permission directly from the copyright holder. To view a copy of this licence, visit http://creativecommons.org/licenses/by/4.0/.

\section{References}

1. Upadhyay A, Jaber BL, Madias NE (2009) Epidemiology of hyponatremia. Semin Nephrol 29(3):227-238. https://doi.org/10. 1016/j.semnephrol.2009.03.004

2. Ayus JC, Wheeler JM, Arieff AI (1992) Postoperative hyponatremic encephalopathy in menstruant women. Ann Intern Med 117(11):891-897

3. Verbalis JG, Goldsmith SR, Greenberg A, Korzelius C, Schrier RW, Sterns RH, Thompson CJ (2013) Diagnosis, evaluation, and treatment of hyponatremia: expert panel recommendations. Am J Med 126(10 Suppl 1):S1-S42. https://doi.org/10.1016/j.amjmed. 2013.07.006

4. Spasovski G, Vanholder R, Allolio B, Annane D, Ball S, Bichet D, Decaux G, Fenske W, Hoorn EJ, Ichai C, Joannidis M, Soupart A, Zietse R, Haller M, van der Veer S, van Biesen W, Nagler E, Hyponatraemia Guideline Development Group (2014) Clinical practice guideline on diagnosis and treatment of hyponatraemia. Eur J Endocrinol / Eur Fed Endocr Soc 170(3):G1-G47. https:// doi.org/10.1530/EJE-13-1020

5. Verbalis JG, Adler S, Schrier RW, Berl T, Zhao Q, Czerwiec FS et al (2011) Efficacy and safety of oral tolvaptan therapy in patients with the syndrome of inappropriate antidiuretic hormone secretion. Eur J Endocrinol/Eur Fed Endocr So 164(5):725-732. https://doi. org/10.1530/EJE-10-1078

6. Amin A, Deitelzweig S, Christian R, Friend K, Lin J, Belk K, Baumer D, Lowe TJ (2012) Evaluation of incremental healthcare resource burden and readmission rates associated with hospitalized hyponatremic patients in the US. J Hosp Med 7(8):634-639. https:// doi.org/10.1002/jhm. 1973

7. Corona G, Giuliani C, Parenti G, Norello D, Verbalis JG, Forti G et al (2013) Moderate hyponatremia is associated with increased risk of mortality: evidence from a meta-analysis. PLoS One 8(12): e80451. https://doi.org/10.1371/journal.pone.0080451

8. Selmer C, Madsen JC, Torp-Pedersen C, Gislason GH, Faber J (2016) Hyponatremia, all-cause mortality, and risk of cancer diagnoses in the primary care setting: A large population study. Eur $\mathbf{J}$ Intern Med 36:36-43. https://doi.org/10.1016/j.ejim.2016.07.028

9. Mannheimer B, Skov J, Falhammar H, Calissendorff J, Lindh JD, Nathanson D (2019) Sex-specific risks of death in patients hospitalized for hyponatremia: a population-based study. Endocrine. 66: 660-665. https://doi.org/10.1007/s12020-019-02073-x

10. Olsson K, Ohlin B, Melander O (2013) Epidemiology and characteristics of hyponatremia in the emergency department. Eur J Intern Med. 24(2):110-116. https://doi.org/10.1016/j.ejim.2012.10.014

11. Liamis G, Milionis H, Elisaf M (2008) A review of drug-induced hyponatremia. Am J Kidney Dis 52(1):144-153. https://doi.org/10. 1053/j.ajkd.2008.03.004

12. Falhammar H, Calissendorff J, Skov J, Nathanson D, Lindh JD, Mannheimer B (2019) Tramadol- and codeine-induced severe hyponatremia: a Swedish population-based case-control study. Eur J Intern Med. 69:20-24. https://doi.org/10.1016/j.ejim.2019. 08.006

13. Falhammar H, Lindh JD, Calissendorff J, Farmand S, Skov J, Nathanson D, Mannheimer B (2018) Differences in associations of antiepileptic drugs and hospitalization due to hyponatremia: a population-based case-control study. Seizure. 59:28-33. https://doi. org/10.1016/j.seizure.2018.04.025

14. Falhammar H, Lindh JD, Calissendorff J, Skov J, Nathanson D, Mannheimer B (2019) Antipsychotics and severe hyponatremia: a Swedish population-based case-control study. Eur J Intern Med. 60: 71-77. https://doi.org/10.1016/j.ejim.2018.11.011

15. Falhammar H, Lindh JD, Calissendorff J, Skov J, Nathanson D, Mannheimer B (2019) Associations of proton pump inhibitors and hospitalization due to hyponatremia: a population-based casecontrol study. Eur J Intern Med 59:65-69. https://doi.org/10.1016/j. ejim.2018.08.012

16. Falhammar H, Skov J, Calissendorff J, Lindh JD, Mannheimer B (2019) Inverse association between glucose-lowering medications and severe hyponatremia: a Swedish population-based case-control study. Endocrine. 67:579-586. https://doi.org/10.1007/s12020019-02160-z

17. Falhammar H, Skov J, Calissendorff J, Lindh JD, Mannheimer B (2020) Reduced risk for hospitalization due to hyponatraemia in lithium treated patients: a Swedish population-based case-control study. J Psychopharmacol:269881120937597. https://doi.org/10. $1177 / 0269881120937597$

18. Li W, Zhang Y, Bouley R, Chen Y, Matsuzaki T, Nunes P et al (2011) Simvastatin enhances aquaporin-2 surface expression and urinary concentration in vasopressin-deficient Brattleboro rats through modulation of Rho GTPase. Am J Physiol Ren Physiol 301(2):F309-F318. https://doi.org/10.1152/ajprenal.00001.2011

19. Elie D, Segal M, Low NC, Mucsi I, Holcroft C, Shulman K et al (2015) Statins in the prevention of lithium-associated diabetes insipidus: preliminary findings. Kidney Int 87(4):862. https://doi. org/10.1038/ki.2014.409

20. Lindquist M (2008) VigiBase, the WHO Global ICSR Database System: Basic facts. Drug Inf J 42(5):409-419. https://doi.org/10. 1177/009286150804200501

21. Israel A, Grossman E (2017) Elevated high-density lipoprotein cholesterol is associated with hyponatremia in hypertensive patients. Am J Med 130(11):1324 e7- e13. https://doi.org/10.1016/j. amjmed.2017.05.030 
22. Powle H, Shet AV, Mendonca AA, Kunhikatta V, Thunga G (2019) PMH38 identification of risk factors associated with hyponatremia in psychiatric patients: a case control study. Value Health 22:S687. https://doi.org/10.1016/j.jval.2019.09.1512

23. Kanchanasurakit S, Saokaew S, Siriplabpla W, Arsu A, Boonmak W, Watcharasiriphong W (2020) Development of a hyponatremia screening tool (ABCDF-S score) for patients with hypertension using thiazide diuretic agents. J Clin Pharm Ther 45:997-1005. https://doi.org/10.1111/jept.13123

24. Ludvigsson JF, Almqvist C, Bonamy AK, Ljung R, Michaelsson $\mathrm{K}$, Neovius M et al (2016) Registers of the Swedish total population and their use in medical research. Eur J Epidemiol 31(2):125-136. https://doi.org/10.1007/s10654-016-0117-y

25. Wettermark B, Hammar N, Fored CM, Leimanis A, Otterblad Olausson P, Bergman U et al (2007) The new Swedish Prescribed Drug Register-opportunities for pharmacoepidemiological research and experience from the first six months. Pharmacoepidemiol Drug Saf 16(7):726-735. https://doi.org/10. 1002/pds. 1294

26. Ludvigsson JF, Svedberg P, Olen O, Bruze G, Neovius M (2019) The longitudinal integrated database for health insurance and labour market studies (LISA) and its use in medical research. Eur J Epidemiol 34(4):423-437. https://doi.org/10.1007/s10654-01900511-8

27. Farmand S, Lindh JD, Calissendorff J, Skov J, Falhammar H, Nathanson D, Mannheimer B (2018) Differences in associations of antidepressants and hospitalization due to hyponatremia. Am J Med 131(1):56-63. https://doi.org/10.1016/j.amjmed.2017.07.025

28. Team RC (2012) R: A language and environment for statistical computing. R Foundation for Statistical Computing, Vienna, Austria. http://www.R-project.org. 2018

29. Salami JA, Warraich H, Valero-Elizondo J, Spatz ES, Desai NR, Rana JS, Virani SS, Blankstein R, Khera A, Blaha MJ, Blumenthal RS, Lloyd-Jones D, Nasir K (2017) National trends in statin use and expenditures in the US adult population from 2002 to 2013 : Insights From the Medical Expenditure Panel Survey. JAMA Cardiol 2(1):56-65. https://doi.org/10.1001/jamacardio.2016.4700

30. Holland-Bill L, Christiansen CF, Heide-Jorgensen U, Ulrichsen SP, Ring T, Jorgensen JO et al (2015) Hyponatremia and mortality risk: a Danish cohort study of 279508 acutely hospitalized patients. Eur J Endocrinol 173(1):71-81. https://doi.org/10.1530/eje-15-0111
31. Zhou Q, Liao JK (2010) Pleiotropic effects of statins.-basic research and clinical perspectives. Circ J 74(5):818-826. https://doi. org/10.1253/circj.cj-10-0110

32. Paulsen L, Holm C, Bech JN, Starklint J, Pedersen EB (2008) Effects of statins on renal sodium and water handling: acute and short-term effects of atorvastatin on renal haemodynamics, tubular function, vasoactive hormones, blood pressure and pulse rate in healthy, normocholesterolemic humans. Nephrol Dial Transplant 23(5):1556-1561. https://doi.org/10.1093/ndt/gfm807

33. Paulsen L, Matthesen SK, Bech JN, Starklint J, Pedersen EB (2010) Acute effects of atorvastatin on glomerular filtration rate, tubular function, blood pressure, and vasoactive hormones in patients with type 2 diabetes. J Clin Pharmacol 50(7):816-822. https://doi.org/ $10.1177 / 0091270009350627$

34. Shepherd J, Kastelein JJ, Bittner V, Deedwania P, Breazna A, Dobson S, Wilson DJ, Zuckerman A, Wenger NK, Treating to New Targets Investigators (2007) Effect of intensive lipid lowering with atorvastatin on renal function in patients with coronary heart disease: the Treating to New Targets (TNT) study. Clin J Am Soc Nephrol 2(6):1131-1139. https://doi.org/10.2215/CJN.04371206

35. Esmeijer K, Dekkers OM, de Fijter JW, Dekker FW, Hoogeveen EK (2019) Effect of different types of statins on kidney function decline and proteinuria: a network meta-analysis. Sci Rep 9(1): 16632. https://doi.org/10.1038/s41598-019-53064-x

36. Holland-Bill L, Christiansen CF, Ulrichsen SP, Ring T, Jorgensen JO, Sorensen HT (2014) Validity of the International Classification of Diseases, 10th revision discharge diagnosis codes for hyponatraemia in the Danish National Registry of Patients. BMJ Open 4(4):e004956. https://doi.org/10.1136/bmjopen-2014004956

37. Korhonen MJ, Helin-Salmivaara A, Huupponen R (2011) Dynamics of long-term statin therapy. Eur J Clin Pharmacol 67(9):925-931. https://doi.org/10.1007/s00228-011-1019-2

38. Pettersson B, Hoffmann M, Wändell P, Levin L (2012) Utilization and costs of lipid modifying therapies following health technology assessment for the new reimbursement scheme in Sweden. Health Policy 104(1):84-91. https://doi.org/10.1016/j.healthpol.2011.10. 010

Publisher's note Springer Nature remains neutral with regard to jurisdictional claims in published maps and institutional affiliations. 